Jansen, P.G.M., Kerkstra, A., Huijer Abu-Saad, H., Zee, J. van der. Differentiated practice and specialization in community nursing: a descriptive study in the Netherlands. Health and Social Care in the Community: 1997, 5(4), 219-226

\begin{tabular}{|l|l|}
\hline $\begin{array}{c}\text { Postprint } \\
\text { Version }\end{array}$ & 1.0 \\
\hline Journal website & $\underline{\text { http://www3.interscience.wiley.com/journal/119159690/abstract }}$ \\
\hline Pubmed link & $10.1111 / \mathrm{j} .1365-2524.1997 . t b 00117 . x$ \\
\hline DOI &
\end{tabular}

This is a NIVEL certified Post Print, more info at http://www.nivel.eu

\title{
Differentiated practice and specialization in community nursing: a descriptive study in the Netherlands
}

\author{
PATRICK G.M. JANSEN ${ }^{1}$ PHD RN, ADA KERKSTRA ${ }^{1}$ PHD, HUDA HUIJER ABU-SAAD ${ }^{2}$ RN \\ PHD AND JOUKE VAN DER ZEE ${ }^{1,3}$, PHD
}

${ }^{1}$ Department of Nursing and Caring Research, Netherlands Institute of Primary Health Care, Utrecht, the Netherlands, Departments of ${ }^{2}$ Nursing Science and ${ }^{3}$ Medical Sociology, University of Maastricht, the Netherlands

Correspondence P.G.M. Jansen, Tulpstraat 29, 7555 BS Hengelo, the Netherlands

\begin{abstract}
Nursing roles are described with respect to two principles on the basis of an inventory study carried out in the Netherlands: differentiated practice and specialization. A total of 58 agencies for community nursing participated in this study (response $=84 \%$ ). In each of these agencies an expert was asked to answer questions by telephone. The results show that a distinction is made between two levels of nurses working in the community: community nurses and community nurse auxiliaries. This distinction is based on the complexity of care, the range of responsibilities and a division between curative and preventive care (adult care vs. mother and child care). Assessment and diagnosis is reserved for nurses at the first level. Second level nurses are responsible for the other components of the nursing process. This study also showed that first level nurses regularly perform tasks that do not require a first level of expertise. It has become obvious with regard to specialization that the generalist work for first level nurses is diminishing: they have to choose either (curative) adult care or (preventive) mother and child care. First and second level nurses also have the opportunity of specializing in one or more patient categories. The aim of these 'areas of special expertise' is to improve professionalism and patient care in community nursing. Based on the results of this study the use of measures to guarantee that the mix of staff meets the demand of care is recommended. In line with this, special measures have to be taken to upgrade the tasks of community nurses. In this respect the use of areas of special expertise and activities relating to coordination of care seem to be appropriate measures.
\end{abstract}

\section{INTRODUCTION}

Home health care is changing. The number of elderly people requiring home care is growing. Technological advances make it possible to provide more complex nursing care at home, which demands special expertise from the nurses. At the same time, governments demand a good price:quality ratio in care (Turton 1984, Taylor 1985, Kenyon et al. 1990, Gibbs et al. 1991). Agencies for community nursing are being forced to use a more businesslike approach. In the Netherlands, the reimbursement system has changed from budgetand 
Jansen, P.G.M., Kerkstra, A., Huijer Abu-Saad, H., Zee, J. van der. Differentiated practice and specialization in community nursing: a descriptive study in the Netherlands. Health and Social Care in the Community: 1997, 5(4), 219-226

input-financing to product- and output-financing. Furthermore, they have stimulated the agencies for community nursing and the home help agencies to cooperate and integrate in order to achieve greater efficiency (Ministry of Public Health 1990). Between 1988 and 1992 the employment of registered nurses decreased, whereas more nurses with lesser qualifications were employed by the agencies (Netherlands Central Bureau of Statistics 1990,1994). Finally, nurses have been shown not to be satisfied with their job because of lack of clarity in responsibilities and tasks (Werner Committee 1991). Because of these changes it has become increasingly important to ensure the efficient use of staff and the provision of high quality care. In this respect attention is paid to two principles of work design: differentiated practice or skill mix and specialization. Both principles are used to ensure that work is carried out by the most appropriate nurse in the most appropriate way. In this paper, the concepts of differentiated practice and specialization in general, and the Dutch situation in particular will be described.

In the Netherlands, a distinction is made between community nurses and community nurse auxiliaries. In line with the Dutch 'Nursing Profile' (National Council for Health Care 1988), 'complexity' of nursing care, and the range of 'responsibilities' are used as the distinguishing characteristics. The differences between the two types of community nurses in the Netherlands can be compared with that between the registered nurse and enrolled nurse in the United Kingdom (Verheij \& Kerkstra 1992) or between Bachelor and Associate nursing degrees in the United States (American Organization of Nurse Executives 1990). Professionally, there is also a difference between nurses and nurse auxiliaries although , hierarchically, they are both managed by a head nurse.

\section{REVIEW OF THE LITERATURE}

The concepts of differentiated practice and specialization will be described in this section, and illustrated by examples from various industrialized countries. For a more detailed description of the literature concerning differentiated practice and specialization in community nursing, please refer to Jansen \& Kerkstra (1995).

\section{Differentiated practice}

Differentiated practice refers to effective use of nursing personnel. Differentiated practice establishes the domain of nursing practice as broad, with multiple responsibilities of varying degree and complexity. It assumes that nurses with different levels of educational preparation, expertise, and background bring differing levels of competence to the workplace. The differentiation of nursing roles is critical in ensuring high-quality care for patients and enhanced work satisfaction for nurses, and the efficient use of nursing and organizational resources. On the premise that individual practitioners with different types of education, competence, and experiences should not be used interchangeably, differentiated practice seeks to ensure that the work of nurses is carried out by the most appropriate nurse in the most appropriate way (Boston 1990). Two different levels of nursing roles can be described. The basic distinction between the two roles centres on complexity of decisionmaking, range of responsibility, and the structure of the situation or setting. The nurse with a Bacherlor's degree (first level) provides direct care to patients and their families with complex interaction in nursing diagnosis from preadmission to post-discharge in structured and unstructured settings and situations. The associate degree nurse (second level) provides direct care to patients and members of a family with common, welldefined nursing diagnosis for a specified work period in structured settings and situations (Primm 1986, 1987, Malloch et al. 1990). Differentiated practice can be compared with the skill mix issue in the United Kingdom. Gibbs et al. (1991) made a distinction between 'grade mix' and 'skill mix'. Grade mix refers to the number of sisters, staff nurses, and auxiliaries required, that is, the number 
Jansen, P.G.M., Kerkstra, A., Huijer Abu-Saad, H., Zee, J. van der. Differentiated practice and specialization in community nursing: a descriptive study in the Netherlands. Health and Social Care in the Community: 1997, 5(4), 219-226

of staff in each grade. Skill mix, on the other hand, refers to the skills and experience of staff within these grades, for example, how many years of experience a staff nurse has in his or her present speciality and whether the nurse has a post-basic qualification in that specialty (Gibbs et al. 1991).

In most industrial countries, a differentiation is made between at least two levels of expertise in community nursing (Verheij \& Kerkstra 1992). In Italy, Luxembourg, Portugal and Spain only first level nurses are employed in home care. This may be due to the fact that community nursing in these countries only started recently. In all countries, the nurses with second level qualifications are always more concerned with personal hygiene care and uncomplicated technical nursing (Hutten \& Kerkstra 1995). It is problematic to give the ratios between the two levels of expertise because there are many divisions in tasks among many types of nurses in many countries. A great deal depends on the definition of first and second levels in each country. However, it is the case that in most countries only very small numbers of second level staff are available, and that Greece, Belgium and France have a higher number of second level nurses than the other countries. It has to be noted, however, that there is no difference in tasks between the first two levels in Belgium. Comparison with the figures from Verheij \& Kerkstra's (1992) study showed that the relative number of second level nurses in the Netherlands and the United Kingdom has increased over the last few years; while, in Belgium, the number of second level nurses has decreased in relative terms (Hutten \& Kerkstra 1995). In the United Kingdom too there is a development which differs from all the other countries: training for enrolled nurses (second level of expertise) is being discontinued. Nursing schools will only produce registered nurses in the future. A new grade (support worker) will be introduced which will presumably be somewhere between an auxiliary and a state enrolled nurse (Verheij \& Kerkstra 1992). The study of Verheij \& Kerkstra (1992) did not reveal many problems in respect of the division of labour among different types of nurses.

\section{Specialization}

Specialization relates to the way in which specialized knowledge is available in the community in order to meet the changing and increasing demands of home care. The international comparative study of Verheij \& Kerkstra (1992) showed two ways in which specialization could be implemented: by a division between (preventive) mother and child care and (curative) adult care, or by a division of labour within curative adult care. The Netherlands, United Kingdom and Finland seem to be the countries in which the division between (preventive) child health care and (curative) adult care is an important issue. The study of Verheij \& Kerkstra (1992) revealed the Netherlands as the only country in which first level nurses delivered both child health care and adult care (most second level nurses cared only for the elderly). In all other countries, most nurses were assigned to one of these categories of care and very often had different training as well. Experiences in the United Kingdom and Finland showed that the division between curative and preventive tasks could lead to difficulty. In the United Kingdom, care of healthy elderly people is considered a task for the health visitor and care of sick elderly people is considered a task for district nurses. Because both types of nurse work in separate teams, communication between them is often difficult. In Finland it was found that the specialist method of working involved a lot of travelling for nurses particularly in sparsely populated areas. This kind of specialization is consequently not always an efficient way of providing care (Verheij \& Kerkstra 1992).

In most countries, clinical nurse specialists are employed for specialization within curative adult care. In many countries there is a limited number of specialist nurses whose main task is usually to advise colleagues. Most agencies in virtually all countries employ specialist nurses or other professionals who are working either in the field or at a higher level in the agency. Sometimes the sources of specialist knowledge are supplemented by sources from outside the agency (Verheij \& Kerkstra 1992). Although the work of clinical nurse 
Jansen, P.G.M., Kerkstra, A., Huijer Abu-Saad, H., Zee, J. van der. Differentiated practice and specialization in community nursing: a descriptive study in the Netherlands. Health and Social Care in the Community: 1997, 5(4), 219-226

specialists is seen to be worthwile, the studies of Haste \& MacDonald (1992) and Griffiths \& Luker (1994) showed that some nurses would prefer to do the work of the specialists themselves, but that they are prevented from doing so by heavy caseloads and lack of time. In the Netherlands 'areas-of-special-expertise' are being developed in order to avoid discontent among nurses, and make specialized knowledge more readily available for nurses at the base. Community nurses and nurse auxiliaries can choose one of these areas and have the opportunity of developing special expertise for a specific category of patients. The nurse performs the general tasks within community nursing in addition to the specific activities regarding area of special expertise (Ketelaars 1992, Wiegers 1992, Jansen \& Kerkstra 1993, Van Bragt 1993, Van Haaren 1994).

In order to get a more detailed overview of differentiated practice and specialization in the Dutch community nursing an inventory study was carried out to address two research questions: firstly, the differences in nursing performance between community nurses and community nurse auxiliaries had to be identified and secondly, the extent to which the roles of community nurse and community nurse auxiliary are specialized had to be ascertained.

\section{METHODS}

Between November 1991 and January 1992 all 69 agencies for community nursing in the Netherlands were approached to participate in a study to describe community nursing in respect of developments concerning differentiated practice and specialization among nurses and nurse auxiliaries. A total of 58 agencies responded positively (response $=84 \%$ ). In each of these agencies someone was appointed that could be considered as an expert concerning differentiated practice and specialization. In most agencies these persons hold the position of staff nurse or clinical nurse specialist.

These experts were asked to answer questions by telephone. An interview schedule was based on a review of organizational literature, and literature about differentiated practice and specialization in nursing was developed. A group of experts discussed the schedule and based on their assessment it was altered. Subsequently, the members of the agencies $(n=58)$ were interviewed. These semi-structured interviews lasted about $45 \mathrm{~min}$. The main topics of the interview are presented in Table 1.

The topics presented in Table 1 were chosen to get a picture of the content of differentiated practice and specialization in community nursing. The results of the interviews were summarized using the statistical program SPSS/PC+. Besides answering questions by telephone the respondents were also asked to send relevant policy documents. About 70 documents were received that could be classified in five categories: general (structure of the agency), differentiated practice, specialization, cooperation between community nursing and home help and others (e.g. nursing assessment and co-ordination of care). These documents gave insight in mission-statements and definitions of concepts (i.e. differentiated practice and specialization). Using these documents, the results of the telephone interview could be further described.

[TABLE 1]

Results 
Jansen, P.G.M., Kerkstra, A., Huijer Abu-Saad, H., Zee, J. van der. Differentiated practice and specialization in community nursing: a descriptive study in the Netherlands. Health and Social Care in the Community: 1997, 5(4), 219-226

\section{Differentiated practice}

Community nurses and community nurse auxiliaries were employed in all agencies. In two agencies no distinction was made between these two types of nurse. In these agencies the nurses and nurse auxiliaries performed the same tasks and had the same responsibilities. In the other 56 agencies, a distinction was made by means of several characteristics. In 53 agencies (95\%) the range of responsibility and the complexity of nursing care were seen as the two most important characteristics to differentiate between community nurses and community nurse auxiliaries. In respect of complexity, community nurses deliver care in highly complex situations; whereas nurse auxiliaries are deployed in less complex situations. Moreover, in most agencies (89\%) nurse auxiliaries do not deliver preventive mother and child care, but only curative adult care; neither do they operate in all stages of the nursing process in most agencies (86\%).

To get a more detailed picture of the difference in responsibility the respondents were asked to indicate who was responsible for the carrying out of the five stages of the nursing process (assessment, diagnosis, planning, implementation and evaluation), and for the continuity and coordination of care. The results are presented in Table 2 for the 53 agencies who made a distinction based on responsibility. It was assumed that community nurses could be responsible for all the stages of the nursing process, as well as the continuity and coordination of care. Accordingly, a distinction is made between the areas for which only community nurses are responsible, and the areas for which both nurses and nurse auxiliaries are responsible.

The differences are particularly obvious in the assessment (gathering data) and the formulation of nursing diagnosis. In 93 and $83 \%$ of the agencies, respectively, the community nurse is solely responsible for this. In most agencies the community nurse auxiliary is responsible for the other components of the nursing process as regards the patients in her own caseload. Furthermore, in most agencies, she is responsible for the continuity of care (e.g. during absenteeism) and in half for the co-ordination of care. Coordination has been described as the guarantee of coherence of care delivered by nurses, home helps, general practitioners and social workers.

In line with the difference in responsibilities there is a difference in accountability. Community nurse auxiliaries are accountable for their own practice, whereas community nurses are accountable for their own practice and the nursing care performed by the nurse auxiliaries. This means that the care delivered by nurse auxiliaries is discussed regularly and evaluated by the nurse and nurse auxiliary together.

In $84 \%$ of the agencies, profiles were present in which the differences between community nurses and community nurse auxiliaries were described. In spite of the presence of these profiles, there was a lack of understanding concerning the differences between the two types of nurse in $41 \%$ of the agencies.

One of the first results presented above was the finding that 'complexity of care' in 95\% of the agencies was seen as an important characteristic in assigning patients either to a nurse or a nurse auxiliary. However, only 39 agencies (67\%) used criteria to determine the complexity of nursing care. This means that in one third of the agencies no attention was paid to the complexity of care, despite the importance attached to it. Examples of criteria that determine complexity are: the number of unpredictable changes in the illness status of the patient, a life-threatening situation, the patient's awareness of the consequences of the illness status, spouse's ability to cope with the nursing situation at home, and the degree of cooperation with other disciplines or professionals. The respondents did however, report that these criteria were not always appropriate, or unclear and needed to be revised.

Besides the criteria cited above others mentioned were: personal judgement of the nurse who does the assessment, workload, and the need for activities reserved for community nurses (e.g. technical nursing like catheterization and intravenous infusion).

All these criteria are meant to ensure that the work of nurses is carried out by the most appropriate nurse in the most appropriate way. However, this is not always the case. The 
Jansen, P.G.M., Kerkstra, A., Huijer Abu-Saad, H., Zee, J. van der. Differentiated practice and specialization in community nursing: a descriptive study in the Netherlands. Health and Social Care in the Community: 1997, 5(4), 219-226

response to the question: 'Do nurses and nurse auxiliaries regularly perform tasks above or below their level of training and experience?' used the respondent's perception of job descriptions (i.e. the Dutch Nursing Profile) as the point of reference.

Most (95\%) of the respondents stated that community nurses regularly perform tasks below their level of expertise. In one third (35\%) of the agencies community nurse auxiliaries regularly perform tasks that require the level of a community nurse. In almost half (48\%) of the agencies the respondents think that nurse auxiliaries regularly perform tasks below their level of expertise, i.e. tasks that could be performed by certified home helps.

Although this study focuses on community nursing, the experts of the agencies were also questioned about the 'boundary area' between community nursing and home help services. In line with the changes stated in the introduction of this paper most of the agencies for community nursing cooperated with home help services: almost $60 \%$ of the agencies cooperated on management-level (between managers) and $90 \%$ on operational level (i.e. cooperation between nurses and home helps). In almost half of the agencies for community nursing job descriptions existed describing the difference between the domain of community nursing and the domain of home help. This difference is described as follows in most agencies: community nurses and community nurse auxiliaries deliver care concentrated on a health care problem whereas certified home helps focus on problems in housekeeping or situations where informal carers can no longer provide the care necessary.

[TABLE 2]

\section{Specialization}

Two types of specialization were used in the agencies: at an organizational level, specialization is between the 'mother and child care' division and the 'adult care' division, and, at an individual level, nurses can specialize in an 'area-of-special-expertise'. The presence of the two types of specialization in 1992 is presented in Fig. 1.

To understand the results in Fig. 1 it is essential to note that community nurses have received training in both adult care, and mother and child care. Nurse auxiliaries are trained to care for elderly people only. Thus, it is exceptional for community nurses to work within one division only. On the other hand, it is exceptional for community nurse auxiliaries to deliver care within both divisions.

Looking at the community nurses first, Fig. 1 shows that in the beginning of 1992 nurses were employed using the all round method in most agencies, i.e. the same nurse takes care of the (preventive) child health care as well as the (curative) adult care. These results also show that in one third of the agencies nurses work in either of the two divisions. As regards the community nurse auxiliaries, in the majority of the agencies, they only take care of elderly people (i.e. in accordance with their training). In addition to this kind of specialization, nurses and nurse auxiliaries specialize in areas of special expertise. In $48 \%(=21+22+5 \%)$ of the agencies community nurses had these specialties and in $44 \%(=3+40 \%)$ of the agencies nurse auxiliaries also had them. Several reasons mentioned for specialization are presented in Table 3.

Three reasons have equal standing for both types of specialization, i.e. maintaining or improving the expertise of the nurses, coping with the changing demand and increased complexity of care. The results also show that the separation into divisions seems to be more often efficiency-based; whereas the areas of special expertise are more often designed to improve the professionalism of community nursing (improving job satisfaction and attractiveness).

The areas of special expertise are based on patient categories in most agencies. These areas are created if specific care is requested in addition to basic care. Specific care relates to nursing care that does not have to be given frequently, and patient categories in which there 
Jansen, P.G.M., Kerkstra, A., Huijer Abu-Saad, H., Zee, J. van der. Differentiated practice and specialization in community nursing: a descriptive study in the Netherlands. Health and Social Care in the Community: 1997, 5(4), 219-226

are a lot of developments. Examples of these areas are: diabetes, patients with AIDS, chronic nonspecific lung disease (CNSLD), dementia, rheumatism, or incontinence. In most agencies, nurse auxiliaries can only choose psycho-geriatrics (dementia) and incontinence. The reason for this is, that the other areas require expertise at the level of a nurse, as these situations are often more complex. In these areas the nurse auxiliary keeps all the literature up to date (81\%), attends educational programs (81\%), stays abreast of trends and innovations (79\%) and attends conferences (78\%). Subsequently, the nurse auxiliary can be consulted by peers in the team and agency with regard to knowledge or skills (76\%). In addition to this special expertise, the nurse performs the general duties within community nursing. In the future, in most agencies the community nurse auxiliary will specialize in both fields: $92 \%$ of the agencies want to make a division between 'mother and child care' and 'adult care' and, as regards the areas of special expertise, $84 \%$ of the agencies will develop them for community nurses and $72 \%$ will develop them for community nurse auxiliaries.

\section{[FIGURE 1]}

[TABLE 3]

\section{DISCUSSION}

This study has shown that there are clear differences between community nurses and community nurse auxiliaries with respect to the assessment and the formulation of nursing diagnoses. These activities are restricted to community nurses. The complexity of care is seen by most respondents as an important distinguishing characteristic; but, in practice, there are not always appropriate criteria in determining the degree of complexity. This study has also shown that the content of community nursing is not always appropriate to the level of training community nurses have received. In almost all agencies community nurses regularly perform tasks below their level of expertise and experience. An important reason for this is probably inappropriate staffing. There are more community nurses employed than nurse auxiliaries, whereas in many nursing situations, basic care is required, which can be delivered by community nurse auxiliaries. We also see that nurse auxiliaries often perform tasks that could be carried out by certified home helps. The main reasons mentioned for this were the long waiting lists that exist for home help services, the shortage of home helps, a lack of clarity about the difference between the domain of home help and the domain of community nursing. Furthermore, variety in the work of first level nurses is diminishing: the all round or generic concept is being abandoned and nurses have to choose either mother and child care or adult care. In addition to these developments in the content of community nursing, this study shows an increased interest in giving nurses and nurse auxiliaries the opportunity to specialize in a specific patient category. Agencies are trying to improve the professionalism of community nursing and home patient care by means of areas of special expertise.

Some recommendations for differentiated practice and specialization in community nursing can be made on the basis of these results. In the first place it is important to have a mix of staff that meets the demand for care. The ratio between nurses and nurse auxiliaries can be determined by the use of valid criteria of complexity. It is expected that this will have consequences for the present ratio of three nurses to one nurse auxiliary in favour of the number of community nurse auxiliaries. 
Jansen, P.G.M., Kerkstra, A., Huijer Abu-Saad, H., Zee, J. van der. Differentiated practice and specialization in community nursing: a descriptive study in the Netherlands. Health and Sociat Care in the Community: 1997, 5(4), 219-226

In addition, it is supposed that more cooperation and integration of home help services and agencies for community nursing promotes clarity in demarcation and harmonization of duties between both types of services. As a result it will be easier to assign an appropriate caregiver to the patient when nursing or home help situations change.

In light of the fact that the expertise of community nurses does not seem to be used adequately, special measures have to be taken to upgrade the tasks for community nurses. Nurses have to be assigned more often to complex nursing situations, and have to concentrate on activities relating to assessment, diagnosis and coordination. Coordination of care is becoming an important issue in community health care, because patients are now discharged from hospitals more quickly and in a poorer state of health. Community nurses need to be given the opportunity to promote patients' interests by coordinating all the care a patient receives from other disciplines and institutions such as general practitioners, home helps, social workers, nursing homes and hospitals. Patients need a guide to a health care system which is becoming increasingly complex. Community nurses are in a strong position to act as a coordinator of care.

Finally, the use of areas of special expertise seems to be an appropriate measure to upgrade both the roles of nurses and nurse auxiliaries. In addition to the employment of clinical nurse specialists, the introduction of these areas can guarantee specialized knowledge in community nursing. An important advantage in these areas is the assurance of quality employment for nurses. These areas will also favour the patient, because it is suggested that a structural improvement of expertise of the nurse (by means of areas-ofspecialexpertise) will lead to a good quality of care. In addition, to save costs patients have to be discharged more quickly from hospitals and this leads to more complex nursing situations at home. To be able to cope with these situations care-givers have to be equipped properly. Areas of special expertise seem to be an appropriate means for this.

\section{ACKNOWLEDGEMENTS}

This research was commissioned by the Dutch Nurses Association (NU91), section Community Nursing.

The study is financed by the Ministry of Health Care in the Netherlands.

\section{REFERENCES}

American Organization of Nurse Executives (1990) Current Issues and Perspectives on Differentiated Practice?.. American Hospital Association, Chicago.

Boston C.M. (1990) Introduction. In Current Issues and Perspectives on Differentiated Practice. American Organization of Nurse Executives, Chicago.

Gibbs I., McCaughan D., Griffiths M. (1991) Skill mix in nursing: a selective review of the literature. Journal of Advanced Nursing 16,242-249.

Griffiths J. \& Luker K. (1994) Community nurse attitudes to the clinical nurse specialist. Nursing Times 90 (17), 39-42.

Haste F.H. \& MacDonald L.D. (1992) The role of the specialist in community nursing: perceptions of specialist and district nurses. International Journal of Nursing Studies 29 (I), 37-47.

Hutten J.B.F. \& Kerkstra A. (1995) Organization and Financing of Home Care in Europe. NIVEL, Utrecht.

Jansen P.G.M. \& Kerkstra A. (1993) Functiedifferentiatie binnen de tkuiszorg. De functies van wijkverpleegkundige, wijkverpleegster en gezinsverzorgende nuder omsckreven. (Differentiated practice and specialization in community nursing. Job descriptions of community nurses, community nurse auxiliaries and home kelps). NIVEL, Utrecht. (In Dutch.) 
Jansen, P.G.M., Kerkstra, A., Huijer Abu-Saad, H., Zee, J. van der. Differentiated practice and specialization in community nursing: a descriptive study in the Netherlands. Health and Social Care in the Community: 1997, 5(4), 219-226

Jansen P.G.M. \& Kerkstra A. (1995) Effecten vanfunctiedifferentiatie binnen de thuiszorg. (Effects of differentiatied practice and specialization in community nursing). NIVEL, Utrecht. (In Dutch.)

Kenyon V., Smith E., Hefty L.V., Bell M.L., McNeil J., Martaus T. (1990) Clinical competencies for community health nursing. Public Health Nursing 7 (I), 33-39.

Ketelaars C. (1992) Goede nazorg door gedifferentieerde wijkverpleegkundigen. (Good follow-up care by specialized community nurses). MGZ 20 (5), 32-34. (In Dutch.)

Malloch K.M., Milton D.A., Jobes M.O. (1990) A model for differentiated nursing practice. Journal of Nursing Administrationa 20 (2), 20-26.

Ministry of Public Health (1990) Heroverwegingsonderzoek 'Van Samenwerken tot samengaan' (Study of reconsidering 'From working together to going together'). Ministry of Public Health, Rijswijk. (In Dutch.)

National Council for Health Care (1988) Verpleegkundig beroepsprofiel. National Council for Health Care, Zoetermeer. (In Dutch.)

Netherlands Central Bureau of Statistics, 1990 and 1994. Vademecum of Health Statistics of The Netherlands. Netherlands Central Bureau of Statistics, Voorburg/ Heerlen. (In Dutch.)

Primm P.L. (1986) Entry into practice: competency statements for BSNs and ADNs. Nursing Outlook 34 (3), 135-137.

Primm P.L. (7987) Differentiated Practice for ADN- and BSNPrepared Nurses. Journal of Professional Nursing 4,218-225.

Taylor B. (1985) The effect of DRGs on home health care. New Jersey's experience suggests DRGs are increasing the need for home care for more acutely ill patients. Nursing Outlook 33 (6),288-289.

Turton P. (1984) Nurses working in the community. Nursing Times 5,4042.

Van Bragt M.J.A.B. (1993) Het gedifferentieerd en allround werken binnen de wijkverpleging. Een onderzoek bij Kruiswerk West-Brabant en Stichting Interkruis Noord-Kennemerland. (Specialization and non-specialization in community nursing. A study carried out at Kruiswerk West-Brubant and Stichting Interkruis Noord-Kennemerland). Rijksuniversiteit Limburg, Maastricht. (In Dutch.)

Van Haaren E. (1994) De expert: Carriere maken met de handen aan het bed. (The expert: make a career with the hands on bed). MGZ 22 (4), 26-28. (In Dutch.)

Verheij R.A. \& Kerkstra A. (1992) International Comparative Study of Community Nursing. Avebury, Aldershot.

Werner Committee (1991) In hoger beroep (In further appeal), Ministry of Public Health, Rijswijk. (In Dutch.)

Wiegers T.A. (1992) Evuluatie van modellen voor aansluiting tussen intramurule specialistische en extramurale uerpleegkundige cara-zorg voor kinderen. (Evaluation of models for connection between specialized hospital care and community nursing care for children with chronic non-specific lung diseases). NIVEL, Utrecht. (In Dutch.) 
Jansen, P.G.M., Kerkstra, A., Huijer Abu-Saad, H., Zee, J. van der. Differentiated practice and specialization in community nursing: a descriptive study in the Netherlands. Health and Socia Care in the Community: 1997, 5(4), 219-226

TABLES AND FIGURES

\begin{tabular}{ll}
\hline Differentiated practice & Specialization \\
\hline $\begin{array}{l}\text { Distinguishing characteristics between nurses } \\
\text { and nurse auxiliaries }\end{array}$ & Kind of specialization \\
$\begin{array}{l}\text { Responsibility conceming different stages of the } \\
\text { nursing process }\end{array}$ & Reasons for specialization \\
$\begin{array}{l}\text { Clarity of division in tasks in job descriptions and practice } \\
\text { The use of criteria for patient-assignment }\end{array}$ & Tasks within specialization \\
\hline
\end{tabular}

Table 1 Main topics of the interview schedule

\begin{tabular}{lll}
\hline $\begin{array}{l}\text { Stage of the } \\
\text { nursing process }\end{array}$ & Community nurse only & $\begin{array}{l}\text { Community nurse or } \\
\text { community nurse auxiliary }\end{array}$ \\
\hline Assessment & 93 & 7 \\
Diagnosis & 83 & 17 \\
Planning & 35 & 65 \\
Implementation & 13 & 87 \\
Evaluation & 25 & 75 \\
Continuity & 15 & 85 \\
Coordination & 46 & 54 \\
\hline
\end{tabular}

Table 2 Differences in responsibilities between community nurses and community nurse auxiliaries in agencies for community nursing, in percentages $(n=53)$

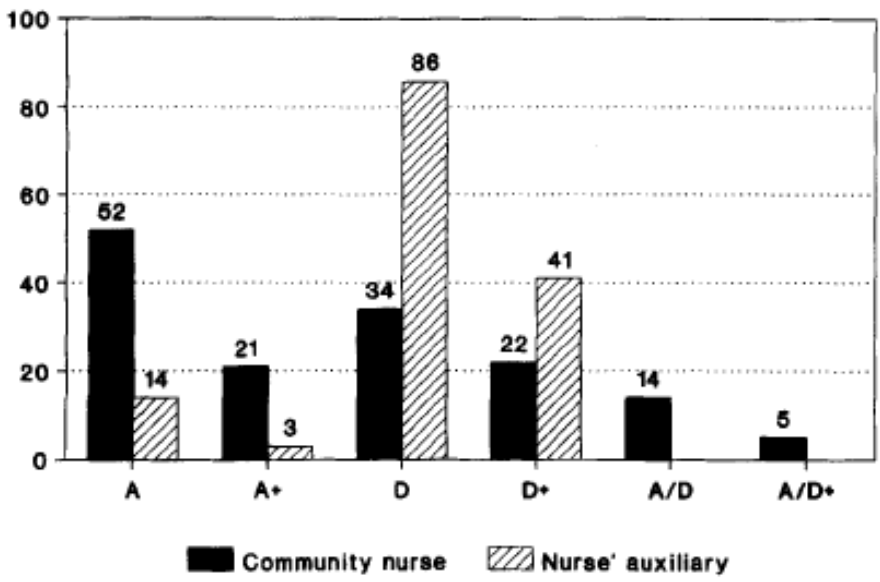

Figure 1 Different types of specialization in agencies for community nursing, as percentages $(n=58)$.

Key: $A$, all round, $A+$, all round with areas of special expertise; $D$, division between 'mother and child care' and 'adult care';

D+, division 'adult care' with areas of special expertise; A/D, all round and two divisions; and $A / D+$, all round with areas of special expertise. The percentages of A, D and $A \cdot D+$ together make $100 \%$.

\begin{tabular}{lll}
\hline & $\begin{array}{l}\text { Division between adult care } \\
\text { and mother and child care }\end{array}$ & $\begin{array}{l}\text { Areas of special } \\
\text { expertise }\end{array}$ \\
\hline Maintains and improve expertise & 93 & 100 \\
Efticient use of personnel & 87 & 63 \\
Changing demand for care & 77 & 76 \\
Increased complexity of care & 77 & 86 \\
Increased amount of care & 72 & 41 \\
Improving job satisfaction & 49 & 76 \\
Improving attraction of nursing & 36 & 61 \\
\hline
\end{tabular}

Table 3 Reasons for specialization, in percentages $(n=58)$ 